\title{
НАПРАВЛЕНИЯ СОВЕРШЕНСТВОВАНИЯ НАЛОГОВОГО КОНТРОЛЯ КАК ФАКТОРА ПРОТИВОДЕЙСТВИЯ УКЛОНЕНИЮ ОТ УПЛАТЫ НАЛОГОВ
}

\author{
(c) 2019 Маккаева Разет Сайд-Аминовна \\ кандидат экономических наук, доцент, кафедра бухучета, анализа и аудита \\ Чеченский государственный университет, Россия, Грозный \\ E-mail: razet1970@mail.ru
}

(c) 2019 Дадаева Фатима Мусаевна

магистрант 2 курса

Чеченский государственный университет, Россия, Грозный

Стабилизационные процессы, протекающие в российской экономике, направленные на предотвращение макроэкономических дисбалансов, отсутствие оптимального равновесного состояния экономики предполагают реализацию консолидированной программы, направленной на не повышение налогового бремени на экономику и активизацию мер по снижению теневого сектора. Особая роль в реализации указанных мер по созданию стабильных налоговых условий отводится системе налогового контроля. Таким образом, актуальность исследования обусловлена необходимостью углубления не только теоретического, но и практического исследования содержания и организации налогового контроля, а также важностью совершенствования механизма реализации новой траектории развития многогранности налогового контроля в условиях стабилизации российской экономики. Объектом исследования является совокупность экономических отношений между налоговыми органами и налогоплательщиками в современных экономических условиях. Предметом исследования являются теоретическое, организационно-управленческое и методическое содержание налогового контроля в условиях стабилизации российской экономики. Практическая значимость исследования заключается в определении направлений развития налогового контроля в условиях стабилизации российской экономики, в разработке методической поддержки контрольных мероприятий в ходе реализации ключевых форм налогового контроля.

Ключевые слова: налоговый контроль, уплата налогов, налоговая база, налоговые обязанности, оптимизация налогообложения, налоговое планирование, этапы налогового планирования.

Налоговый контроль призван противодействовать любой в нелегальной деятельности, что усиливает его влияние на обеспечение профилактики экономических и иных видов преступлений, а также сдерживание попыток легализации доходов, полученных в результате преступной деятельности. Несмотря на то, что основная нагрузка по пресечению таких преступлений, безусловно, ложится на правоохранительные органы, роль налоговых администраций в раскрытии источников происхождения преступных доходов нельзя недооценивать, поскольку усилия налогового контроля направлены на нейтрализацию рисков, негативно влияющих на экономическую безопасность государства [1]. Наиболее распространенными формами налогового мошенничества, характерными для всех сфер теневого бизнеса, являются осуществление деятельности без уплаты налогов на доходы, уклонение от уплаты НДС и страховых взносов [2], а также системные процессы размывания (эрозии) [3] налоговой базы в результате налогового планирования (оптимизации налоговых обязательств).

При разграничении понятий минимизации и оптимизации налогов в научной литературе акцентируется фактор правомерности применяемых налогоплательщиком способов сокращения налоговой обязанности. В частности, минимизация налогов рассматривается как более широкое понятие, учитывающее возможность любого уменьшения размера налоговых платежей, и включающее в себя как правомерные способы снижения налогового бремени (налоговое планирование, налоговая оптимизация, избежание налогов или tax avoidance), так и противоправную деятельность (уклонение от уплаты налогов или tax avasion) [4].

Понятия «оптимизация налогообложения» и «налоговое планирование», как правило, боль- 
шинством специалистов рассматриваются как равнозначные. Вместе с тем можно установить и смысловые различия между планированием и оптимизацией налогов, основанные на том, что налоговое планирование может пониматься более широко, как совокупность действий налогоплательщика по прогнозированию налоговых последствий своей экономической деятельности.

Целеполагающим результатом таких действий разумного и добросовестного налогоплательщика будет принятие решений относительно условий применения налогового законодательства в конкретной ситуации, которые не всегда будут предполагать оптимизационный эффект с точки зрения решения задачи налоговой экономии. Вполне допустимо принятие решения, менее выгодного для налогоплательщика в спорной ситуации, которое приведет к увеличению налоговых обязательств, однако в долгосрочном периоде позволит исключить риски доначисления налогов и привлечения к ответственности, что влечет существенные финансовые потери. Таким образом, налоговое планирование может быть определено как совокупность легитимных действий и решений налогоплательщика по оптимизации налоговых издержек.

Вместе с тем существует и проблема злоупотребления налогоплательщиками предоставленными правами и возможностями, использования пробелов в законодательном регулировании, построении оптимизационных моделей с целью получения необоснованной налоговой выгоды при реализации стратегии агрессивного налогового планирования. Международные организации рассматривают проблему агрессивного налогового планирования в качестве глобальной. Так, Группа разработки финансовых мер борьбы с отмыванием денег (Financial Action Task Force или ФАТФ) акцентирует внимание на проблеме привлечения в преступных целях квалифицированных специалистов, оказывающих услуги в сфере инвестиционных и финансовых операций, созданию офшорных компаний, трастов, иных решений в сфере налоговой оптимизации [5]. В качестве мероприятий по защите государственных интересов от агрессивного налогового планирования в Сеульской декларации ОЭСР 2006 года рекомендуется применение таких мер как установление режима контролируемых сделок, предполагающего раскрытие информации о сделках, которые могут вести к злоупотреблени- ям налоговыми правами и уклонению от налогообложения [6].

Уклонение от уплаты налогов оказывает существенное влияние на экономику всех стран, негативно воздействуя на бюджетную систему, искажая международную конкуренцию и движение капитала, что побуждает правительства проектировать и реализовывать системные меры по противодействию этому явлению. М. Кин (M. Keеn) отмечает, что проблема несоблюдения налогового законодательства непосредственно зависит от налоговой политики и мер по ее реализации, которые должны опираться на исследование причин, условий и факторов, побуждающих к нарушению закона для разработки предупредительных действий [7]. С целью разграничения легальных и агрессивных приемов сокращения налоговых обязательств целесообразно исследование методического инструментария налогового планирования.

Виды налогового планирования, его формы и методы в научной и учебной литературе представлены широким разнообразием классификаций. Их обобщение позволяет выделить ряд критериев, по которым различаются видовые характеристики налогового планирования. Каждой из них присущи организационные и методические особенности осуществления:

1. По субъекту реализации различают корпоративное налоговое планирование, осуществляемое хозяйствующими субъектами; холдинговое, осуществляемое в группе компаний; индивидуальное, осуществляемое физическими лицами.

2. По периоду охвата выделяется оперативное (на месяц, квартал), текущее (на финансовый год), перспективное (долгосрочное) налоговое планирование.

3. По реализуемым целям можно определить текущее и стратегическое налоговое планирование.

4. По уровню налоговой юрисдикции ведения деятельности выделяются: международное, национальное, региональное налоговое планирование.

5. По отрасли и направлению деятельности дифференцируются налоговое планирование коммерческих и некоммерческих операций; производственных и торговых операций в отраслевом разрезе, в том числе - добычи полезных ископаемых; инновационной и внедренческой деятельности. 
6. По масштабам деятельности различают налоговое планирование малого бизнеса; средних предприятий; крупнейших налогоплательщиков.

Этапы налогового планирования рассматриваются в научных исследованиях в соответствии со стадиями жизненного цикла организации (проекта, договора). Так, на первой стадии (организационной), наряду с выбором организационно-правовой формы ведения деятельности и определением основных видов деятельности, формируется миссия, цели и задачи организации (проекта, договора), а также намечается территория фактической деятельности (физическое присутствие, наличие активов) и внутренняя структура организации с учетом характера и целей деятельности. Принятые решения дают основания для концептуального обоснования в рамках процедур налогового планирования сферы налоговой обязанности. Кроме того, представление о возможной территории фактической деятельности, о перспективах осуществления трансграничных операций и их направлениях, позволяет определить концептуальные условия устранения проблемы двойного налогообложения.

Вторая стадия (регистрационная) предполагает определение наиболее выгодного с точки зрения минимизации налоговых платежей месте регистрации организации, расположении ее исполнительных органов, обособленных подразделений, дочерних и зависимых организаций. На данной стадии процедуры налогового планирования предполагают формальный выбор одного из установленных законодательством налоговых режимов с учетом гражданско-правовых ограничений, а также сопровождение процесса регистрации с целью контроля соблюдения установленных законодательством ограничений, процедур и сроков.

Третья стадия (стадия текущего налогового планирования) предполагает содержательное тактическое насыщение концепции, разработанной на предыдущих стадиях, посредством использования широкого методического инструментария налогового планирования, включая максимально возможное применение права на налоговые льготы, освобождения, преференции; систематическое отслеживание изменений налогового законодательства и правоприменительной практики с целью оперативных корректировок тактики налогового планирования; использование оптимальных условий договорных отношений с целью трансформации налоговых последствий совершаемых сделок; прогнозирование налоговой базы, отслеживание тенденций ее изменения и анализ причин таких изменений; разработка и систематическая корректировка учетной политики для целей налогообложения, выбор оптимальных для данного налогоплательщика методов учета налогооблагаемой базы; использование преимуществ маркетинговой политики; обоснование рыночного уровня применяемых цен в сделках с взаимозависимыми лицами; отслеживание, сопровождение, учет и анализ контролируемых сделок. На данной стадии осуществляется разработка локальных нормативных актов, необходимых для выполнения требований налогового законодательства и минимизации риска ошибок в исчислении и уплате налогов, включая методику расчета налоговых обязательств, учетные регистры для формирования налоговой базы, правила консолидации данных разных подразделений при составлении налоговой отчетности.

На четвертой стадии (стратегической) налоговое планирование обеспечивает обоснование и сопровождение решений по развитию и расширению существующего бизнеса и его операционных сегментов, что предполагает рациональное размещение активов, центров формирования прибыли и издержек, обоснование инвестиционных программ, условий и методов привлечения дополнительных финансовых, кредитных и инвестиционных ресурсов, внедрения инновационных технологий и проведения научных исследований. Оптимизация принимаемых решений в рамках налогового планирования, учитывая множество разнообразных льгот, предоставляемых на уровне правительства и регионов, позволяет максимизировать эффект налоговых преференций и частично компенсировать расходы на уплату налогов.

В качестве важной стадии налогового планирования можно также выделить стадию анализа, оценки и контроля налоговых рисков (контрольная стадия налогового планирования). Налоговые риски, возникающие в деятельности налогоплательщика, имеют как объективный характер (невозможность со стороны налогоплательщика повлиять на возникновение и перспективы развития рисковой ситуации), так и субъективный (допускается активное противодействие налогоплательщика негативным эффектам рискообра- 
зующего фактора). Кроме того, налоговые риски можно классифицировать по двум основным группам - внешние и внутренние. Внешние риски негативного развития налоговых отношений характеризуются слабой степенью влияния налогоплательщика. Области проявления внешних налоговых рисков включают в себя три основные сферы - политические риски, риски налогового контроля, риски со стороны недобросовестных контрагентов.

Политические риски, в свою очередь, определяются стратегическими и тактическими действиями государства при реализации налоговой политики и включают в себя следующие направления:

1. Стратегические изменения налоговой политики, требующие пересмотра сложившихся бизнес-процессов и влияющих на повышение уровня налоговых изъятий. Так, например, серьезную угрозу для российских налогоплательщиков, особенно для организаций малого и среднего предпринимательства, представляют такие концептуальные положения налоговой политики, как предполагаемая с 2018 года полная отмена единого налога на вмененный доход. Негативно воздействует на ожидания подавляющего большинства налогоплательщиков и нестабильность политических решений по поводу уровня тарифов страховых взносов.

2. Корректировки технических условий расчета налоговых обязательств, ведущие к пересмотру сложившихся договорных отношений. В рамках данной группы налоговых рисков можно рассматривать перспективы изменения подходов к налоговому контролю трансфертного ценообразования, включения в налогооблагаемую базу расчетным путем дополнительных показателей.

3. Появление судебных прецедентов или официальных разъяснений уполномоченных органов, изменяющих правоприменительную практику и сформировавшиеся подходы в определении момента возникновения налоговых обязательств, условий расчета налоговой базы, порядка применения налоговых льгот и преференций.

Учитывая подчиненное положение налогоплательщика в структуре налогового правоотношения как лица, на которого законом возложена обязанность уплаты налогов, существенную угрозу экономической стабильности деятельности представляют риски налогового контро- ля, среди которых можно выделить следующие обстоятельства:

1) формальное соответствие налогоплательщика критериям отбора для налогового контроля, которое провоцирует инициацию выездной налоговой проверки при отсутствии реальных фактов нарушений налогового законодательства, обеспечивая при этом базис конфликта с проверяющими, вынужденными обеспечивать «результативность» контроля;

2) избыточный контроль (не обусловленный объективными факторами повышенный интерес фискальных органов к деятельности налогоплательщика, в том числе так называемые «заказные» проверки, частые проверки крупных налогоплательщиков, обладающих финансовыми возможностями для уплаты доначисленных сумм);

3) выявление в рамках процедур налогового контроля ошибок и упущений в определении реального уровня налоговых обязательств, что влечет доначисление налогов, пеней и штрафных санкций, негативно влияющих на финансовой положение налогоплательщика;

4) неэффективная защита интересов налогоплательщика в налоговых спорах - на уровне досудебного урегулирования, составления апелляционной жалобы и рассмотрения исков по итогам налоговых проверок в судебных инстанциях;

5) значительные трудозатраты на исполнение требований налоговых органов по представлению сведений и документов, необходимых для проведения мероприятий налогового контроля, в том числе - в рамках встречных проверок контрагентов налогоплательщика:

6) возникновение дополнительных издержек для защиты интересов при налогообложении (получение банковской гарантии, поручительства, привлечение налоговых консультантов);

7) ограничения деятельности вследствие применения налоговыми органами обеспечительных процедур (приостановление операций по счетам, арест имущества, запрет на проведение операций по реализации, исполнение инкассовых поручений), в том числе - при избыточном либо некачественном налоговом администрировании.

Таким образом, реализация налоговых отношений сопряжена не только с проблемами правоприменения, но и с проблемами соблюдения 
закона. Налогоплательщики, мотивированные на максимизацию эффективности деятельности организаций, заинтересованы в использовании способов снижения налоговых издержек, не противоречащих законодательству. Добросовестность плательщика, выражающаяся в стремлении сократить налоговые риски, следовать нормам закона и сотрудничать с налоговыми органами, рассматривается в настоящее время как значимый признак социальной ответственности бизнеса, обеспечивающий его рыночную ценность [8].

Эффективность функционирования налогового планирования как неотъемлемой части системы управления деятельностью налогоплательщика обеспечивается при соблюдении следующих принципиальных положений: законности, то есть соответствия действий налогоплательщика существующему законодательству; экономической целесообразности; индивидуальности подходов к выбору инструментов налогового планирования, приемлемых для конкретной ситуации.

В основе стратегии уклонения от уплаты налогов лежит использование пробелов в законодательном регулировании, недостаточной методической проработки соглашений об устранении двойного налогообложения, различий в национальных системах налогового права с целью получения необоснованной налоговой выгоды. Основные признаки уклонения от уплаты налогов включают в себя [9]:

1) наличие сложной структуры совершаемых сделок при отсутствии ярко выраженной экономической цели их осуществления;

2) недостаточную прозрачность сделок;

3) использование норм закона для формулирования оснований для неуплаты налога, противоречащих стандартным условиям признания объекта обложения либо применения налоговых льгот («налоговые лазейки»).

Современные методы противодействия уклонению от уплаты налогов при реализации агрессивного налогового планирования и легализации преступных доходов основаны на использовании информационных технологий, дополнительном налогообложении контролируемых иностранных компаний, углубленном анализе условий сделок между взаимосвязанными лицами, применении метода тонкой капитализации при оценке налоговых последствий займов между взаимозависимыми лицами, проти- водействие трансфертному ценообразованию [10]. В настоящее время сформирована система мониторинга прибыли транснациональных корпораций, что позволяет налоговым органам разных государств оперативно обмениваться информацией о прибыли, налоговых ставках и льготах, полученных налогоплательщиками в каждой стране, а также о совершенных им конкретных сделках.

При исследовании уклонения от уплаты налогов, его феноменологических характеристик и мер противодействия этому явлению, на наш взгляд, необходимо различать два основных способа уклонения, реализуемых на практике:

1) прямое сознательное нарушение налогового законодательства, что предполагает игнорирование или несоблюдение установленных законом требований или ограничений;

2) косвенное нарушение налогового законодательства, когда установленные нормы и правила формально соблюдены, но смысловое толкование законодательных положений искажено в интересах налогоплательщика.

Если первый способ можно охарактеризовать как криминальный, то реализация второго способа требует серьезной интеллектуальной и организационной поддержки, реализуемой в рамках агрессивного налогового планирования при содействии квалифицированных специалистов (юристов, профессиональных бухгалтеров), оказывающих услуги в сфере инвестиционных и финансовых операций, созданию офшорных компаний, трастов, подставных фирм.

Соответственно, если криминальные схемы, основанные на явном нарушении закона, могут быть достаточно быстро обнаружены и пресечены налоговыми администрациями и правоохранительными органами, то выявление сознательных действий налогоплательщика по уклонению при формальном соблюдении закона может быть сильно затруднено, несмотря на предсказуемость возможных решений и широкую известность типичных схем.

Кроме того, выбор метода уклонения от уплаты налогов различается в зависимости от статуса, резидентства и имиджевых характеристик налогоплательщика. Так, можно предположить, что иностранные инвесторы-нерезиденты, особенно транснациональные корпорации, в значительно меньшей степени готовы прямо нарушать закон, опасаясь не столько налоговых санкций, сколько репутационных потерь в гло- 
бальном масштабе. При этом именно транснациональные компании обнаруживают большую склонность к агрессивному налоговому планированию, манипулированию договорными условиями при переводе полученной прибыли, широкому использованию офшорных юрисдикций для максимизации оптимизационных эффектов.

Для национальных компаний и компаний со смешанным капиталом риски нарушения закона в любой форме могут повлечь серьезные последствия вплоть до ликвидации бизнеса и личной ответственности его владельцев, что определяет модель поведения налогоплательщика при осуществлении деятельности, в том числе и возможный выбор прямого уклонения при наличии уверенности в сокрытии налоговой выгоды за счет личных связей, подкупа должностных лиц контролирующих органов, а также избежание возможных санкций за счет привлечения номинальных руководителей, вывода активов и иных криминальных действий.

Вместе с тем возможность применения прямого криминального уклонения от уплаты налогов непосредственно связана с низким уровнем контрольных и предупредительных мер со стороны государства, включая недостаточность правового регулирования. В современных условиях, учитывая распространение лучших практик налогового администрирования, возможности для криминального уклонения, а, следовательно, и сфера его применения, существенно сужены. Соответственно, наибольшее распространение приобретает уклонение от уплаты налогов косвенным методом посредством оптимизационных схем в силу пониженного уровня риска обнаружения признаков уклонения и квалификации полученной налоговой выгоды как необоснованной. Это обстоятельство снижает конкурентоспособность компаний, ведущих деятельность на национальных рынках, прежде всего - малого и среднего бизнеса, которые вынуждены нести значительно более высокий уровень налогового бремени. Предупреждение указанных негативных эффектов обеспечивается усилением мер налогового контроля в отношении масштабных схем агрессивного налогового планирования.

\section{Библиографический список}

1. Адвокатова А.С. Налоговый контроль в условиях модификации отношений налоговых органов и налогоплательщиков: дис.к.э. н.: 08.00.10 / Адвокатова Алена Станиславовна.- Москва, 2019. - 229 с.

2. Брызгалина, А.В.Налоги и налоговое право учебник для вузов / А.В.Брызгалин.- М.: Аналитика-Пресс, $-1998 .-608$ с.

3. Бюджет - 2017: возвращение к трехлетнему циклу// Финансы. 2017. № 1.- С.3-8.

4. Васильева Н.М. Электронная коммерция как правовая категория. Юрист. 2006;(5).

5. Встреча с руководителем Федеральной налоговой службы Михаилом Мишустиным [Электронный ресурс] / Официальный сайт Президента России - режим доступа: http://kremlin.ru/events/president/news/53288 (Дата обращения: 24.08.2019).

6. Гончаренко Л. И., Малкова Ю.В., Адвокатова А.С. Актуальные проблемы налоговой системы в условиях цифровой экономики. Экономика. Налоги. Право. 2018;11(2):166-171.

7. Гринкевич Л.С., Жалонкина И.Ю. Новый порядок применения контрольно-кассовой техники: причины введения и последствия // Сибирская финансовая школа. 2017. № 3. - С.60-64.

8. Грунина Д.К. Контрольно-надзорная деятельность как фактор повышения деловой активности налоговых органов // Экономика. Налоги. Право. 2018. № 3. С. 132

9. Данные по формам статистической налоговой отчётности ФНС России 2-НК [Электронный ресурс].- Режим доступа: https://www.nalog.ru/rn77/related_activities/statistics_and_analytics/forms/6763053/ (Дата обращения: 23.08.2019).

10. Данные по формам статистической налоговой отчётности ФНС России № 1-НМ [Электронный ресурс].Режим доступа: https://www.nalog.ru/rn20/related_activities/statistics_and_analytics/forms/7216714/. 